\title{
POLÍTICAS DE LO MÍNIMO: GENEALOGÍAS COLONIALES EN LOS MAPAS DEL SUR
}

\author{
Karina Bidaseca \\ CONICET/UNSAM/UBA \\ Marta Sierra \\ Kenyon College, USA
}

\begin{abstract}
Resumen: La propuesta de este ensayo es ahondar en las genealogías de la matriz violentogenética del proyecto occidental en la vida cotidiana de la considerada "última selk' nam" de Tierra de Fuego, Lola Kiepja, narrada por la antropóloga Anne Chapman. Decidimos ubicar este texto en las producciones artísticas de la casa - como metáfora femenina de lo nacional - para anclar en las que llamamos "políticas de lo mínimo" como formas de resistencia a la matriz colonial desde una perspectiva transdisciplinaria. A partir de una epistemología política de un "Tercer Feminismo", como presentado por Bidaseca, nos aventuramos hacia un rescate de lo femenino menor, buscando dibujar las coordenadas de lo que Marta Sierra llama un "mapa en ruinas". Este mapa subalterno se reconstruye sobre la fisura de un feminismo mestizo, aprisionado entre lo que la chicana Gloria Anzaldúa denomina un estado de permanente "nepantlismo mental", hecho de lo "heredado, lo adquirido, lo impuesto". " El objetivo de este trabajo es hacer una reflexión sobre cómo distintos modos de violencia contra lo femenino (como lo menor, lo obsceno - lo dejado fuera de la escena social) nos permita inscribir una genealogía de la memoria poscolonial en diálogos sur-sur que atraviese distintas geografías y mapas de poder. Palabras clave: política de lo mínimo; violencia; memoria poscolonial.
\end{abstract}

\section{Introducción. El cuerpo como texto ${ }^{2}$}

Cuando nos conocimos, ambas nos encontrábamos trabajando en perspectivas teóricas y epistémicas surgidas desde el trabajo de la artista visual guatemalteca

Copyright $\odot 2014$ by Revista Estudos Feministas.

1 Gloria ANZALDÚA, 1999, p. 104.

${ }^{2}$ Una versión anterior fue enviada al Simposio "Diálogo Trans-Pacífico y Sur-Sur: Perspectivas alternativas a la cultura y pensamiento eurocéntrico y noroccidental". Santiago de Chile, 7 al 10 de enero de 2013. 
contemporánea Regina José Galindo. Nacida en 1974 en Guatemala, en la época del genocidio que dejó 260.000 muertxs y desaparecidxs ( $83 \%$ de ellas eran indígenas mayas), artista conceptual reconocida internacionalmente, criticada por el establishment local por las intervenciones agresivas en su cuerpo, tal como la que cinceló en su pierna con un cuchillo la palabra indeleble escrita en los cuerpos de las mujeres de Guatemala o Juárez, "Perra". O en la sombra de un cuerpo desnudo amarrado a una cama vertical, texto sobre el que se proyecta el título de una noticia: "Treinta violaciones en sólo dos meses", en la intervención "El dolor en un pañuelo" (1999), los abusos cometidos en contra de la mujer en Guatemala. "(279) Golpes" es un "Performance sonoro. Encerrada en un cubículo, sin que nadie pueda verme, me doy un golpe por cada mujer asesinada en Guatemala del 1 de enero al 9 de junio del 2005."3 La violencia ficcional sobre el cuerpo femenino, desnudo, ultrajado, proyecta un cuerpo social construido en un lugar-tiempo, en una "realidad que es violenta. $Y$, dice, ya nadie se conmueve". ${ }^{4}$

En estos tiempos, los cuerpos femeninos - entre la guerra y la (ficción de) la paz ${ }^{5}$ - se erigen como el síntoma de la especificidad de las guerras contemporáneas, y la "guerra contra el terrorismo", declarada como tal a partir del 11 de setiembre de 2001.

Ciudad Juárez, Estado de Chihuahua, frontera Norte de México con El Paso, Texas. Desembarco de las maquiladoras. ${ }^{6}$ Allí obscenamente se exhibe la violencia de la ficción de la paz,

la relación directa que existe entre capital y muerte, entre acumulación y concentración desreguladas y el sacrificio de mujeres pobres, morenas, mestizas, devoradas por la hendija donde se articulan economía monetaria y economía simbólica, control de recursos y poder de muerte.

Catatumbo, departamento Norte de Santander, frontera Norte de Colombia con Maracaibo, Venezuela. Desembarco de las transnacionales. Allí obscenamente se exhibe la violencia de la guerra entre el narcotráfico, el paramilitarismo, la guerrilla, las transnacionales, y el sufrimiento y muerte de mujeres que no cesa. Y así, podemos mencionar otros lugares que conforman esa cartografía latinoamericana de violencias, cuyo signo más visible se encarna en los cuerpos femeninos. La violencia constituye esa lengua particular que se lee en el cuerpo como texto.

El conocimiento situado necesita recortar de esa geografía el Sur; más precisamente, el Cono Sur. Allí es posible rastrear las huellas de la violencia durante las dictaduras de los años setenta (Argentina y Chile, en este caso). Como señala Nelly Richard ${ }^{8}$ la política y lo político son las categorías más vigiladas y censuradas por el totalitarismo; la cultura y el arte se convierten en campos alternativos que permiten transmutar hacia figuraciones indirectas lo reprimido por el sistema dictatorial. Abordaremos los trabajos de dos artistas de Argentina y Chile: la obra de la artista plástica Diana Dowek y la escritora chilena Carmen Berenguer, que desde lenguajes disímiles, abordan lugares y problemas en común.

\footnotetext{
${ }^{3}$ Ver: www.reginajosegalindo.com.

${ }^{4}$ Entrevista a Regina José Galindo. Christelle Faucoulanche. En Revista Vozal. http://www.revistavozal.org/ perrasxoloitzcuintles/wp-content/uploads/entrevista-R.-jose-galindo-final.pdf. Consultado el 14 de febrero de 2013 , p. 1

${ }^{5}$ Slavoj ZIZEK, 1999, citado por Karina BIDASECA, 2010.

- Las maquilas son centros de producción en expansión desde la apertura de los mercados en los años 1990. Están localizadas preferentemente en países pobres del Sur (como México, Guatemala, Honduras, Marruecos, Bangladesh o la India).

7 Rita SEGATO, 2003, p. 1

${ }^{8}$ Nelly RICHARD, 2007.
} 


\section{Naciste pintada/Pintar la pintura}

En su libro Naciste pintada, Berenguer produce una cartografía urbana desde una mirada anti-monumento construida a partir del recorrido trunco y una perspectiva caleidoscópica en que la ciudad se transforma en un espacio desarticulado, como refleja el extenso poema "Ruinas" con que se abre el libro y que dialoga con la estética creacionista de Vicente Huidobro.

Siguiendo la tradición de la literatura del post-golpe inaugurada con Lumpérica de Diamela Eltit, Santiago es descripta como una ciudad sitiada, de una movilidad dificultosa o imposible..$^{10}$ Sin embargo, frente a esta imagen, Berenguer traza los recorridos de una localidad urbana de resistencia que construye lo que Deleuze y Guattari ${ }^{11}$ denominan como el espacio liso del nómade, localizado pero no limitado, y caracterizado como táctil y sonoro.

Como un recurso de la memoria, estas cartografías urbanas imaginarias de Berenguer develan la relación profunda entre lo imaginativo y lo empírico en la visión.

Aunque la intención política es evidente en la tercera sección del libro de carácter abiertamente testimonial, considero que Berenguer rescata este uso político de la visión en todo el texto al construir una ciudad invisible a los ojos del poder, una ciudad secreta que bien adhiere a las características de lo que Bhabha denomina como el "tercer espacio" o el "entre-lugar" ${ }^{12}$ de enunciación, un espacio que destruye el espejo de la representación y desde el cual las ubicaciones culturales y materiales pueden reapropiarse, traducirse y leerse críticamente. ${ }^{13}$

La estética del paisaje en la obra pictórica de Dowek está claramente ligada a la idea de nación, proyectado en instantáneas que parten desde una temporalidad proyectada en la serie "Lo que vendrá" (1972) en el espacio de lo público, lo abierto, a lo cotidiano, al objeto aparentemente trivial. Anteponiendo la metáfora del alambre como recurso plástico que claramente alude a los campos de concentración de la Alemania bajo el nazismo, pero también a la propiedad (de la tierra), llega a pintar a las muñecas alambradas y hasta llega a aparecer pintada por ella misma. En la artista el cuerpo es el cuerpo tela, el soporte sobre el cual se marca el poder represivo. En el catálogo "Pintar la pintura" de Dowek irrumpe la siguiente leyenda: "Pintar la pintura, todo ha sido dicho, todo ha sido hecho. Sin embargo, recomienzo cada día como la primera vez". ${ }^{14}$ Aquí la obra de arte expulsa a su creador; en cada acto de creación la artista es expulsada y debe recomenzar. Luego, Dowek ${ }^{15}$ escribe: "Mi yo cirujano opera con un pincel o escapelo, o cuchillo, o simplemente con la mano".

Simbiosis en paralelo con la obra de Berenguer, de modo que la tela soporte debe liberar su cuerpo aplastado. Aludiendo de manera explícita a las "cartografías deseantes" de Néstor Perlongher, Berenguer transforma lo urbano en un espejismo donde lo menor agita y recorre una gran ciudad-cadáver, como señala citando a Huidobro: "Chile aparece como un inmenso caballo muerto, tendido en las laderas de Los Andes bajo un gran revuelo de cuervos". ${ }^{16}$

9 Carmen BERENGUER, 1999.

${ }^{10}$ María Eugenia BRITO, 1994, citada por Marta SIERRA, 2012.

11 Giles DELEUZE y Felix GUATTARI, 2005, p. 382.

12 Para Edward Soja este "tercer espacio", que identifica con la dimensión del "espacio vivido" de Lefebvre, "un lugar de encuentro estratégico para fomentar la acción política colectiva contra todas las formas humanas de opresión" (Edward SOJA, 2010, p. 195, citado por SIERRA, 2012).

${ }^{13}$ Homi BHABHA, 1995, citado por SIERRA, 2012.

${ }^{14}$ Alicia DOWEK, 1981, citado por Silvia MARRUBE, 2012.

${ }^{15}$ DOWEK, 1972, citado por MARRUBE, 2012, p. 35.

16 BERENGUER, 1999. 


\section{Memorias poscoloniales hechas cuerpo}

La propuesta epistémico-política del "Tercer Feminismo" requiere acudir a procesos históricos recientes, pero vinculados a una matriz colonial para pensar en la genealogía de las violencias. La dominación sobre las mujeres tienen una larga data, tan larga que se confunde con la historia de la humanidad. ${ }^{17}$ Tal vez podamos asumir que el genocidio como práctica social fundado con nuestra propia historia nacional y regional imprimió la matriz que conocemos y repudiamos. ${ }^{18}$ En este apartado nos interesa indagar en la obra de las artistas lo que llamamos las políticas de lo mínimo; la deconstrucción del símbolo de la casa por medio de una conjunción de los "motivos nacionales" y los "motivos íntimos" 19 y en la representación de la "hoja en blanco" - del papel y del lienzo - como expresión de una estética contra-narrativa.

\section{La Casa, política de lo mínimo}

La representación de la violencia del Estado dictatorial de los setenta atravesando todos los espacios en la vida cotidiana ha sido trabajada en diferentes campos disciplinarios. Para Argentina, la tesis de Silvia Marrube ${ }^{20}$ sobre la obra de tres artistas plásticas argentinas: Diana Dowek, Mildred Burton y Alicia Carletti, permiten iluminar algunos aspectos.

Sus obras son testimonio que han dejado plasmado estas artistas mujeres, mientras los sucesos siniestros sucedían en función de un orden fundado en la pedagogía de la violencia. La metaforización de la obra de estas artistas durante la última dictadura militar permiten acercar una reflexión sobre la casa como el resguardo del terror de Estado, en las casas es donde ingresan y se procesan los acontecimientos políticos, y en el comúnmente subestimado "cotidiano femenino": pequeños objetos diarios de la existencia surgen en esas obras como recursos estéticos con diferentes tratamientos. Un estética de lo mínimo, lo minúsculo. El Yo mayúsculo y el yo minúsculo. "La mujer batalla con dos representaciones lingüísticas del yo: un "Yo" con mayúsculas (el sujeto maestro, el depósito de la tradición cultural) y un "yo" con minúsculas (el sujeto personal con una raza y un género específico)". ${ }^{21}$

Naciste pintada traza un mapa, no como una mímesis sino como una heterotopía, en el sentido de Foucault, ${ }^{22}$ como un reflejo doble, un contra-emplazamiento, en que la ciudad y la casa representan, impugnan e invierten los emplazamientos reales en el interior de la cultura. ${ }^{23}$ Quizás sea en la revolucionaria relación entre lo privado y lo público en donde ambas artistas perciben el espacio de modo más verídico. Mientras Berenguer muestra de manera más evidente que el espacio es un punto de articulación que nos permite entender cómo complejas dinámicas de relaciones sociales se construyen, decaen y eventualmente se renuevan. ${ }^{24}$ Naciste Pintada se abre con la sección de "Casa cotidiana", en que la paseante construye una "movilidad opaca y ciega". 25 "Lo casero" que entraña a la casa se encuentra también en la obra de Berenguer que da subtítulo a una sección como "metáforas caseras", aludiendo así a los modos de habitar esa gran casa-ciudad

\footnotetext{
17 SEGATO, 2003.

18 BIDASECA, 2012

19 Raquel OLEA, 2003, citado por SIERRA, 2012.

20 Silvia MARRUBE, 2012.

${ }^{21}$ MINH-HA y TRINH, 1989, p. 6

22 Michel FOUCAULT, 2010.

23 BERENGUER, 1999, p. 70.

24 Doreen MASSEY, 2005.

25 BERENGUER, 1999, p. 251.
} 
que su poesía reconstruye como una miniatura que "se parece" y no, señala la voz poética, a ciertos paisajes urbanos contemporáneos.

Berenguer y Dowek establecen una "arquitectura de lo extraño", ${ }^{26}$ en que lo que es familiar y ha sido reprimido retorna. En esta economía espacial del texto de Berenguer, lo doméstico extraño implica una mirada opaca que, al contrario de aquella que fija y hace visible, produce lo doméstico como un reflejo distorsionado, y a la casa como un espacio anómalo y en fuga.

En el collage de las artistas argentinas como recurso plástico, surgen representaciones mutiladas. Restos, fragmentos, se alienan afines a la "desconexión sintáctica" a la que alude Richard ${ }^{27}$ para caracterizar al neovanguardismo chileno de la misma época. ${ }^{28} \mathrm{En}$ ese orden militar patriarcal, la mujer, al no identificarse con el poder militar, quedó de algún modo resguardada como el "sujeto prístino" de esta ominosa historia.

El tema de la memoria es central en nuestro texto. Es fundante en el proyecto poético de Naciste pintada de registrar y documentar lo que ha quedado ausente. Y casi reconociendo su imposibilidad, el texto se mueve hacia lo fragmentario y lo disperso, se atomiza en una cadena de sensaciones y sonidos, una red textual del "aullido y el lamento de un parto" que atraviesa genealogías sin tiempo que confluyen en un paradigma único y solitario de dolor, luto y locura. ${ }^{29}$ No sólo desde la perspectiva nomádica que Rosi Braidotti señala como central en la conciencia crítica de los conocimientos subyugados, ${ }^{30}$ sino también en la memoria como un cuerpo rebelde, que Ana Forcinito describe como central en la obra de autoras latinoamericanas de la post-dictadura, y que se inscribe en la denuncia de los cuerpos domesticados o desaparecidos en la región. ${ }^{31}$

De igual modo, en Dowek se recrea la vivencia de un espacio a partir de las experiencias del encierro y la tortura con la metáfora del alambrado sujetando al sí mismo, para incorporar una dimensión siniestra de la cotidianeidad. Desde este registro, la voz femenina apenas audible aparece en la tela de Dowek y en la multitud de Santiago, que adquiere protagonismo y se recontextualiza en los testimonios, los "recados de la prisión", que dan cuerpo a la "casa inmóvil" de la última sección del libro de la chilena.

Podemos reconstruir un diálogo implícito entre esta imagen y las fotos de prisionerxs desaparecidxs durante las últimas dictaduras de Argentina y Chile, imágenes que se conocieron en los medios con posterioridad como las más conmovedoras, quizás, que muestran fragmentos de los cuerpos torturados, con manos y piernas atadas, algunos con sogas de persianas, fotos que formaban parte de los archivos de la Comisión Interamericana de Derechos Humanos (CIDH) y que salieron a la luz luego de 32 años hace pocos meses atrás. El informe incluye curiosamente mapas que marcan las zonas con cuerpos encontrados, y trazan ciclos de las corrientes para revelar a Buenos Aires como el lugar donde fueron arrojados los cuerpos. Los archivos ubican los cuerpos y narran su historia: sus rasgos físicos y su fisionomía, los métodos con los que fueron torturados, las posibles causas de su muerte. ${ }^{32}$

\footnotetext{
26 SIERRA, 2012.

27 RICHARD, 2007.

${ }^{28}$ En Chile la Escuela de Avanzada (neovanguardismo), a diferencia del arte militante, acude a cuerpos fragmentados, a la dispersión, interrupción (RICHARD, 2007).

29 OLEA, 2003, p. 172.

${ }^{30}$ Rosi BRAIDOTTI, 1994. p. 27.

${ }^{31}$ Ana FORCINITO, 2004.

${ }^{32}$ El informe describe, por ejemplo, el hallazgo de un "cuerpo de sexo femenino, cutis blanco, cabello negro, estatura 1,60 metros; complexión mediana; de unos treinta años y con un tiempo de muerte aproximado de entre 20 y 25 días". "Presentaba indicios externos de violencia: signos de violación, probablemente con
} 
El título de "naciste pintada" es la referencia final en que una de las detenidas es pintada para ocultar las huellas de la tortura. En Dowek la posibilidad del autorretrato contrarresta la ironía de un retrato hecho por otro. En ambas, la "hoja en blanco" irrumpe como contra-narrativa. En palabras de Berenguer: "Esta es una página blanca, la blancura es signo de pureza, ninguna letra podría mancharla, no bastaría su grafía. Esta página representa el occidente, podría citar al blanco de la página en blanco..." que es también el símbolo de una literatura nacional "macha" y "occidental". ${ }^{33}$ Las estéticas de devenir de Berenguer ${ }^{34}$ y Dowek ${ }^{35}$ corren la mirada hacia los bordes de lo representable, y elaboran un malestar irresuelto. Ambas proponen nuevas formas de habitar un lugar, el gran espacio de la urbe, o el espacio imaginario del estado-nación del cual fueron desplazadxs por el paradigma que Berenguer bien define como "macho" y "occidental". Como señalan las contundentes palabras de Joan, que Naciste pintada nombra como la "muchacha nativa del Norte": "Esa canalla viene a imponerme sus leyes y su lengua. Esa canalla neocolonial quiere encerrarme en mi país, tranca su puerta y me tira perros adiestrados. Esa canalla quiere que yo sea extraña en mi casita". ${ }^{36}$

\section{Oberturas. Mapas de la praxis feminista}

Un "mapa en ruinas", como metaforiza Marta Sierra, ${ }^{37}$ en el cual el feminismo poscolonial está pensando justamente esas intersecciones, esos espacios "in-between" donde se articulan las diferencias comunes y se elaboran estrategias de identidad colectivas, como afirma Homi Bhabha. "Desde esta geografía transitoria, se arma el mapa de los borderlands, un mapa precario y fugaz construido a partir de la mirada de la mestiza divida entre dos tierras. Estos mapas frágiles implican una nueva forma de práctica teórica", señala Chela Sandoval. Partiendo de las fracturas que propone la teoría posmodernista, Sandoval define una "conciencia de los borderlands", que es diferencial, cinética y móvil, que funciona tanto dentro como fuera de la ideología dominante. Leída a la luz del texto de Anzaldúa, la propuesta de Sandoval ofrece la perspectiva crítica mestiza como una actividad descolonizadora que estructura un método y una teoría para armar coaliciones políticas, identitarias y estéticas que son centrales en lo que denomina como un feminismo de tercera generación en el siglo XXI. El espacio del feminismo, o lo que Sandoval denomina como el "tercer feminismo", se caracteriza como una topografía cultural, un mapa móvil hecho de repositorios que el sujeto subyugado puede ocupar o abandonar, algo que permite la descolonización de sus relaciones con condiciones reales de existencia.

Ya la feminista negra Audre Lorde, en esa gran antología "Esta puente mi espalda. Voces de mujeres tercermundistas en los Estados Unidos" (1988), refería a la casa en tanto metodología de emancipación. Bajo el título, "La casa del amo no se destruye con las herramientas del amo".

objetos punzantes; fracturas múltiples y el codo izquierdo destrozado; múltiples fracturas en ambas piernas con indicios de haber sido atadas; enorme cantidad de hematomas diseminados por todo el cuerpo; destrozo total del cráneo y del macizo oseofacial". Ver el artículo, "Imágenes que prueban los vuelos de la muerte" de Alejandra Dandan. p. 12, 15 dic. 2011 . Disponible en: http://www.pagina12.com.ar/diario/elpais/ 1-183431-2011-12-15.html.

${ }^{33}$ Berenguer señala: "La literatura nacional es narcisa y tiene una hilera de nombres masculinos, tiene la confirmación de una firma masculina, es sexuada. La literatura chilena es macha y su estética es occidental" (BERENGUER, 1999, p. 32)

34 BERENGUER, 1999.

35 DOWEK, 2013.

${ }^{36}$ BERENGUER, 1999, p. 35

37 SIERRA, 2012 
El Tercer Feminismo del Sur ${ }^{38}$ se erige como el lugar de enunciación de la fisura que habita la subalterna, el equivalente al "nepantla", en lengua náhuatl, que para la feminista chicana Gloria Anzaldúa se sitúa en el lugar fronterizo donde es posible cerrar la herida colonial para que nazca una "nueva mestiza"; esa cicatriz en el alma, como nos dice Moira Millán. ${ }^{39}$

La reflexión en torno a las condiciones específicas del espacio, de la subjetividad de género y la sexualidad, parte de la categoría de encierro - ya sea real o imaginado, literal o metafórico - como una instancia demarcatoria de un perímetro de circulación autorizado para las mujeres. O también del dominio territorial del Barón sobre el cuerpo femenino que "ahora se volvió capaz de controlar de forma irrestricta su territorio". ${ }^{40}$ A ella alude el relato histórico oral de la huerquén Moira Millán, que le fuera transmitido por su abuela materna: 41

\begin{abstract}
A partir de Noviembre de 1878 y hasta Enero 1885 se consolidó para los pueblos del sur del continente la invasión del estado argentino mediante un genocidio, que se llevó a delante bajo el nombre de "Conquista al desierto", pero no había desierto para conquistar, sino un extenso territorio poblado por naciones milenarias, con las que el pueblo Mapuche cohabitaba, los Aonikén, llamados por nosotros tehuelches, y más al sur los Onas, Yámanas, y Alalkalufes. Mientras que del otro lado de la cordillera nuestro pueblo vivía una pesadilla similar con otro nombre: "Pacificación de la Araucanía". Se instalaron campos de concentración y exterminio en donde concentraban a centenares de familias en condiciones inhumanas y cometiendo contra ellas todo tipo de vejámenes y torturas. Los campos de concentración y exterminio más grandes fueron el de Valcheta y Chichinales (provincia de Río Negro).
\end{abstract}

"Como en toda guerra las mujeres son un botín, como símbolo de sometimiento, el ejército argentino violaba y torturaba a las mujeres", ${ }^{42}$ expresa el relato de Moira Millán.

Entretanto, las políticas de la memoria que el movimiento femenino necesita construir, desde los pensamientos del feminismo de color, resisten a la espiral del silencio y al laberinto temporal. La abyección de la violencia en los cadáveres de mujeres yace en la base donde se apoya y apunta el orden social falogocéntrico. El Tercer Feminismo es aquél que logrando interpelar a la sociedad toda sobre las violencias contra el género, se inscriba en una genealogía de la memoria poscolonial. Este proyecto requiere recuperar una memoria epistémica que no omita las contribuciones del feminismo chicano (el sur del norte), pero que se sitúe en nuestro Sur. En la construcción de esa memoria femenina de los sures, se hace imperativo no olvidar. Los aportes que desde las artes nos brindan Dowek y Berenguer, y así el recado que nos ha dejado Lola, "De vez en cuando camino al revés, es mi modo de recordar... si caminara hacia delante, te podría contar cómo es el olvido". Lola Kiepja, última chamán selk'nam.

\title{
Referencias
}

ANZALDÚA, Gloria. Borderlands/La Frontera. The new Mestiza. Aunt Lute Books: San Francisco University Press, 1999 [1987].

BHABHA, Homi. The Location of Culture. London and New York: Routledge. 2. ed. 1995. BERENGUER, Carmen. Naciste pintada. Chile: Cuarto Propio, 1999.

38 BIDASECA, 2012

${ }^{39}$ Moira MILLÁN, 2011.

40 SEGATO, 2003, p. 12.

${ }^{41}$ MILLÁN, 2011 , p. 130.

${ }^{42}$ MILLÁN, 2011. 
BIDASECA, Karina; SIERRA, Marta. Postales femeninas desde el fin del mundo. El Sur y las políticas de la memoria, Bs. As.: Ed. Godot, 2012.

BIDASECA, Karina. "Sitios liminales entre cordilleras invisibles. Cartografías poscoloniales del Tercer Feminismo". In: SIERRA, Marta (Comp.). Cartografías imaginarias: Espacios de resistencia y crisis en América Latina, Chile: Cuarto Propio. En prensa.

BRAIDOTTI, Rosi. Nomadic Subjects. Embodiment and Sexual Difference in Contemporary Feminist Theory. Introduction. "By Way of Nomadism." New York: Columbia UP, 1994. 1-39.

BRITO, María Eugenia. Campos minados. Literatura post-golpe en Chile. Chile: Editorial cuarto propio. 2da. Edición, 1994.

DELEUZE, Giles; Félix GUATTARI. A Thousand Plateaus. Capitalism and Schizophrenia. Traducción e introducción de Brian Massumi. Minneapolis, London: Minnesota University Press. 11. edición, 2005.

DOWEK, Diana. La Pintura es un Campo de Batalla. Buenos Aires, Asunto Impreso Ediciones, 2013.

FOUCAULT, Michel. "Espacios diferentes". El cuerpo utópico. Las heterotopías. Traducción: Víctor Goldstein. Buenos Aires: Nueva visión, 2010. p. 63-81.

FORCINITO, Ana. Memorias y Nomadías: géneros y cuerpos en los márgenes del posfeminismo. Chile: Editorial Cuarto Propio, 2004.

LORDE, Audre. "La casa del amo no se destruye con las herramientas del amo". In: MORAGA, Cherríe; CASTILLO, Ana (Ed.). Esta puente mi espalda. Voces de mujeres tercermundistas en los Estados Unidos. San Francisco: ISM Press, 1988.

MARRUBE, Silvia. "Violencia de Estado y vida cotidiana. La obra de Diana Dowek, Mildred Burton y Alicia Carletti entre 1974 y 1981". 2012. Tesis (Maestría en Historia del Arte Argentino y Latinoamericano) - IDAES-Universidad Nacional de San Martín, Buenos Aires.

MASSEY, Doreen. Space, Place and Gender. 4th ed. Minneapolis: U of Minnesota, 2005.

MILLÁN, Moira. "Mujer Mapuche. Explotación colonial sobre el territorio corporal". In: BIDASECA, Karina (Co-comp.). Feminismos y poscolonialidad. Descolonizando el feminismo desde y en América latina. Buenos Aires: Godot, 201 1. p. 127-135.

MINH-HA, Trinh. Woman, Native, Other: Writing Postcoloniality and Feminism. Bloomington: Indiana University Press, 1989.

OLEA, Raquel. "Oralidad y relocalización de sujeto en la producción de dos escritoras chilenas". Revista de Crítica Literaria Latinoamericana. XXIX, n. 58, p. 215-23, 2003.

PERLONGHER, Néstor. "Los devenires minoritarios". Prosa Plebeya. Buenos Aires: Colihue, 2008.

RICHARD, Nelly. Fracturas de la memoria. Arte y pensamiento crítico, Buenos Aires: Siglo XXI, 2007.

SIERRA, Marta. "Los devenires urbanos de Carmen Berenguer: reflexiones en torno a la visualidad y el espacio". In: Chile Urbano: Literatura, arte, cine. Santiago Chile, Universidad Católica, 2012. En prensa.

SEGATO, Rita. La escritura en el cuerpo de las mujeres asesinadas en Ciudad Juárez, México: Universidad Sor Juana Inés de la Cruz, 2003.

[Recebido em fevereiro de 2014 e aceito para publicação em abril de 2014]

\section{Minority Politics: Colonial Genealogies in the Maps of the South}

Abstract: This article explores an alternative genealogy to Western Occidental epistemologies by focusing on subaltern minority politics. We center on an analysis of the relationship between Lola Kiepja, considered as the "last Selk'nam" in Tierra del Fuego, and the anthropologist Anne Chapman. From a transdisciplinary approach, this work focuses on the domestic artistic productions 
- a feminine metaphor for the national - as a site of postcolonial resistance. From the perspective
of a "Third Feminism", as presented by Bidaseca, we sought to reconstruct what Marta Sierra
called the "mapa en ruinas" of such subaltern feminist epistemologies. Built on the gaps of a
mestizo, hybrid feminism, in a state of "nepantlismo mental" made of "inherited, acquired, and
imposed" elements, as stated by Gloria Anzaldúa, we study different representations of this
feminine (as the "minor", the "obscene" - that which is left out the social scene). Our ultimate goal
is to reconstruct the genealogy of a transnational and postcolonial memory that crosses over
different geographies and power maps.
Key Words: Politics of a Subaltern Feminist Representation; Violence; Post-Colonial Memory. 